\title{
As novas narrativas da ficção televisiva e a Internet ${ }^{1}$
}

\section{The new narratives of television fiction and the Internet}

\section{RESUMO}

A constante retroalimentação entre a televisão e as novas tecnologias expande os limites de interpretação e configura novos modelos narrativos e novas modalidades de cooperação textual que estão modificando de maneira radical os paradigmas de texto e de interpretação. A incorporação crescente dos usuários na Rede propicia a configuração de um entorno midiático onde as fronteiras entre produção e recepção são cada vez mais difusas, o que está transformando a Rede no principal aliado da ficção televisiva. Neste artigo (realizado no âmbito de uma pesquisa sobre a construção da identidade juvenil na ficção televisiva e nas novas tecnologias), são repassados os principais marcos da parceria crescente entre televisão e internet, à luz das diferentes modalidades de retroalimentação propiciadas pela nova transmedia storytelling.

Palavras-chave: ficção televisiva, internet, intertextualidade, identidade juvenil

\section{ABSTRACT}

The constant feedback between television and new technologies expands the limits of interpretation and configures new narrative models and new modalities of textual cooperation, which are modifying the textual and interpretative paradigms in a radical way. The increasing incorporation of users to the Internet favours the configuration of a media environment, whose boundaries between production and reception are incessantly reshaping, and which is turning the Internet into the main ally for television fiction. In this article (conducted in the frame of an investigation concerning the construction of youth identity on television fiction and new technologies), the main landmarks of the increasing alliance between television and the Internet are examined in the light of the different modalities of feedback favoured by the new transmedia storytelling.
* Catedrática do Departamento de Jornalismo e Ciências da Comunicação da Universidad Autónoma de Barcelona. Especialista em análise do audiovisual e coordenadora espanhola do Obitel (Observatório Ibero-Americano de Ficção Televisiva). Entre outros livros, publicou El discurso televisivo sobre la inmigración (Omega) e El espectador televisivo (Gedisa).

1. Este artigo foi escrito no âmbito do projeto de pesquisa $A$ representação dos jovens na ficção televisiva catalã e espanhola: construção de identidades, atribuição de papéis sociais e correspondência com a realidade. No projeto, dirigido pela professora Charo Lacalle e financiado pela Agencia Catalana de la Juventud de Catalunya, participaram as pesquisadoras Beatriz Gómez, Manuela Russo, Marilluz Sánchez, Lucía Trabajo e Berta Trullàs.

Keywords: television fiction, internet, intertextuality, youth identity 
INTERNET NASCIA EM 1989, 36 anos depois do início da televisão. A Rede das redes não é só um meio de comunicação cuja difusão capi-

lar permite conectar instantaneamente pontos antípodas no planeta, exatamente como havia imaginado Marinetti, o fundador do Futurismo, no histórico manifesto publicado no jornal Le Figaro, em 20 de fevereiro de 1909, ao falar de uma rede que teria conectado o mundo. A internet nos forneceu a infraestrutura tecnológica necessária para superar a diversidade de formas comunicativas, permitindo a transformação de quase todas estas para o formato digital. A Rede constitui um dos instrumentos privilegiados para poder representar configurações socioculturais baseadas na sinergia, como a "inteligência coletiva” definida por Pierre Lévy (1997). A internet é um meta-meio interativo e comunitário. Um meio de meios.

A Rede comprime o espaço, o converte em uma espécie de "não-lugar" (Augé, 1993) e fundamenta sua estrutura em sua instantaneidade. A internet é o que há de mais próximo da versão do senso comum de "aldeia global" de McLuhan, onde é possível encontrar pessoas provenientes de qualquer lugar da Terra, mas também falar com elas com uma imediatez semelhante à da comunicação face a face e com uma intimidade própria da comunicação por cartas ou do diário íntimo.

A autonomia da comunicação no que diz respeito ao tempo e ao espaço é, seguramente, uma das razões pelas quais a internet transformou-se no (meta) meio que mais contribuiu até agora para desmassificar a audiência, desmultiplicando o "leitor modelo" (Eco, 1979) e estendendo os limites do texto e da interpretação até a própria recepção. Nas palavras de Lévy, a distinção entre autores e leitores, produtores e espectadores, criadores e intérpretes mescla-se no ciberespaço para constituir um "circuito" no qual cada participante trabalha com o objetivo de sustentar a atividade dos outros (Lévy, 1995).

$\mathrm{O}$ ambiente virtual situa o usuário em algum ponto equidistante entre a intimidade e a extimidade ${ }^{1}$ e permite sua integração na inteligência coletiva sem prejuízo de sua identidade individual. Esta mescla perfeita de comunicação pessoal, mas ao mesmo tempo compartilhada, permite ao espectadorusuário integrar-se em comunidades virtuais, que promovem o debate entre indivíduos reunidos pelos mesmos valores e pelos mesmos interesses. Mas diferente das comunidades interpretativas da televisão, imbuídas também por um espírito de grupo compartilhado, ainda que constituídas em coletivos sociais de curta duração (Lemish, 1985: 289), as comunidades virtuais da internet transcendem o tempo e o espaço da recepção para converterem-se em uma verdadeira extensão do programa. Pensemos, por exemplo, nos fóruns, chats, paródias no YouTube etc, que são gerados sobre a ficção televisiva dirigidos ao target juvenil, além da atividade febril levada a cabo pelos internautas nas redes sociais.

Os sociólogos da cultura utilizam o conceito de narrativas transmediáticas (transmedia storytelling) para definir o ir e vir das histórias construída em diferentes meios de comunicação, cada um dos quais realiza sua própria contribuição à interpretação da história global (Jenkins, 2006) ${ }^{2}$. Apesar de as histórias em quadrinhos (comics) constituírem embasamentos excepcionais das narrativas transmediáticas, a retroalimentação entre a ficção televisiva e a internet representa sem dúvida a expressão máxima desse ir e vir das história entre um meio e outro. Tal retroalimentação constitui o suporte privilegiado de uma relação inextricável entre o texto e o espectador empírico, que est modificando os paradigmas semióticos da textualidade e da interpretação.

Após a primeira fase de desenvolvimento da internet (denominada, retrospectivamente, web 1.0), a web 2.0 ou web interativa realiza o caminho de ida e volta da comunicação mediática, o horizonte tanto ansiado pela Teoria da Informação desde que Shannon e Weaver formularam seu influente modelo de 1948. Os primeiros passos da web 3.0 (a chamada data web), prefiguram o cenário da web semântica, percebida como a transição definitiva em direção à inteligência artificial mediante serviços capazes de extrair o sentido e a ordem da rede existente. O desenvolvimento da visão em ${ }_{3} \mathrm{D}$ (antecipada já em espaço virtuais como, por exemplo, no Second Life ou Habbo) também se vislumbra no horizonte da web 3.0

Diferentemente dos vínculos intermediáticos do passado, de caráter eminentemente transtextual (Genette, 1984: 9) e baseados principalmente na adaptação de histórias (remakes) ou de formatos, assim como nas referências de um texto a outro (intertextualidade), a relação entre a televisão e as novas tecnologias tem caráter orgânico. As extensões dos relatos-matriz às novas tecnologia (principalmente a internet, mas também videojogos e telefone celular) se integram com os (e não nos) próprios programas, produzindo formas "narrativas tão extensas que não podem ser contidas em um único meio" (Jenkins, 2006: 95). Os hipertextos ${ }^{3}$ resultantes das novas narrativas transmediáticas caracterizamse principalmente por sua hibridização, entendida como "a capacidade de um texto de absorver e transformar elementos de todos os espaços culturais" (Jenkins, 2006: 112). ${ }^{4}$

O cinema, meio audiovisual mais inovador do século XX, começa construir narrativas transmediáticas no final dos anos 1980, com o intuito de rentabilizar os grandes investimentos que requeriam os Blockbusters de New Hollywood $^{5}$. No entanto, como assinala Henry Jenkins, o conceito de transmedia storytelling não tinha sido introduzido no debate público até 1999, e tem origem
2. Como assinala Carlos Scolari, outros autores utilizam denominaçōes diferentes para definir as narrative media studies, transmedial narratology, cross media, multimodality, multiplatafororma etc (Scolari, 2009: 2).

3. "Refiro-me a toda relação que una um de hipotexto) a um texto anterior A (que chamarei, claro, hipertexto) sobre o qual ele se enxerte de uma maneira que não (Genette, 1992 : 9) (NT). 4. O conceito de espaço cultural, utilizado por
Jenkins para definir a ibridização, é particuarmente interessante en relação aos hipertextos das narrativas transmediáticas, cia implicitata à utilização do termo no âmbito dos Estudos Pós-coloniais para definir a resistência ou a adaptacaão dos produtos
culturais ocidentais outros ambientes.

Em uma tentativa de construir a genealogia das narrativas transmediáticas,
Paul Levitz (presidente) e editor da DC Comics) reporta-se a The Wizard of $\mathrm{Of}(\mathrm{O}$ mágico de OZ, Victor Fleming, 1939), um do imaginário cinematográ fico dos norte-americanos. $<$ http://www.convergenceculture.org/weblog/2006/11/ foe_transmedia_properties. php\#more> Acesso
em 29 set 2009 . 
no sucesso de A Bruxa de Blair (Blair Witch Project, Daniel Myrick e Eduardo Sánchez) ${ }^{6}$, uma pequena produção independente que surgiu como uma atividade de fãs na Web mais de um ano antes de sua eclosão nos cinemas - ainda que o fenômeno da transmedia storytelling tenha alcançado seu epígono com Matrix, em 2003, considerado pela revista Newsweek precisamente o "o ano de Matrix" (Jenkins, 2006: 2007).

Inspirado em A Bruxa de Blair, Chris Pike inaugurou as narrativas mediáticas da televisão um ano depois com Dawson's Creek ${ }^{7}$. A série contava com uma página web atualizada diariamente (Dawson's Desktop), que permitia aos usuários lerem os e-mails dos protagonistas, seus projetos para o diário, seus roteiros e até seus rascunhos (Jenkins, 2006: 115).

Com o auge do sitcom norte-americano nos anos 1960, a ficção televisiva viveu uma primeira idade de ouro sem parâmetro até nossos dias. A segunda idade de ouro (época atual) caracteriza-se, ao contrário, pela qualidade e variedade de boa parte dos subgêneros dramáticos (profissional, de relações, ação, mistério, ficção científica etc), assim como pela crescente inter-relação entre a televisão e as novas tecnologias. De fato, a extensão das narrativas televisivas às novas tecnologias é considerada um dos principais motores da renovação da ficção televisiva, em um momento em que o cinema se dedica mais a conservar seu patrimônio semiótico do que a inovar, ou então recorre a gêneros ainda raros ou quando não completamente ausentes das salas de cinema (sobretudo o documental). No entanto, vale lembrar que é precisamente o específico da televisão (a recepção concomitante com outras atividades do lar e o caráter seriado que caracteriza a estrutura de seus relatos), que converte a retroalimentação em uma prática produtivo-interpretativa.

C casamento entre a televisão e as novas tecnologias, sobre o qual se firma a crescente construção e o impulso das narrativas transmediáticas, é, sem dúvida, por amor (por parte dos destinatários), mas também por conveniência (por parte dos emissores), e está rejuvenescendo um meio cuja rentabilidade em curto prazo passa precisamente pela parceria com as novas tecnologias. A expansão da conexão de banda larga e os avanços para a compressão de imagens originaram um novo modo de ver a televisão, com o consequente e constante incremento das emissões de televisão via internet. O usuário tem a possibilidade de escolher o horário que prefere e iniciar a visualização de um programa e interrompê-lo para poder continuar em qualquer outro momento.

As próximas páginas pretendem ser uma fotografia dessa interseção entre a ficção televisiva e as novas tecnologias (principalmente a internet), que tem seu ponto de ancoragem no surgimento e na rápida consolidação da web 2.0.

\section{A COMUNICAÇÃO NA WEB 2.0}

O grupo editorial O'Reilly Media e MediaLive International cunhou em $2004{ }^{\circ}$ conceito de web 2.o e, um ano mais tarde, surgiu o artigo de Tim O'Reilly, What is the web 2.o. Design Patterns and Business Models for the Next Generation of Software, onde a Rede já não era mais entendida unicamente como uma simples vitrine de conteúdos multimídia, mas também como uma plataforma aberta, construída e baseada na participação de seus usuários. A ideia do conhecimento aberto veio se desenvolvendo a partir de cinco conceitos cunhados por outros tantos autores: "interatividade" (Berners-Lee, 200o), "inteligência coletiva" (Lévy, 2004), "multidões inteligentes" (Rheingold, 2002), "sabedoria das multidões" (Surowiecki, 2004) e "arquitetura da participação" (O’Reilly, 2004).

Segundo Tim O'Reilly (idem), os princípios básicos da web 2.0 são sete: 1 ) a World Wide Web como plataforma de trabalho; 2) o reforço da inteligência coletiva; 3) a gestão de base dos dados enquanto competência primária; 4) constante atualização gratuita dos dados e dos serviços disponíveis na Rede 5) a utilização de modelos de programação rápidos e a busca da simplicidade 6) o software não limitado a um único dispositivo e 7) o valor agregado das experiências dos internautas. Consequentemente, o desenvolvimento da web 2.o não é apenas do tipo tecnológico, mas também de natureza social. A web 2.o facilita a troca e a cooperação entre indivíduos e gera novas posibilidades de construção social do conhecimento, do compartilhar o saber mediante estruturas abertas e horizontais, que promovem a intercriatividade e a inteligência coletiva para benefício da comunidade.

A verdadeira força da Rede reside precisamente em sua estrutura do tipo end to end (eze), ou seja, em sua descentralização, e no fato de que a inteligência se situa nos extremos da rede (network) e está representada por usuários ou por clientes individuais, enquanto a infraestrutura em si mesma é "estúpida" e constitui unicamente um meio de transmissão "acéfalo" (Lessig, 2006: 83). A web 2.0 define a fase atual do incessante processo evolutivo de Internet caracterizada por sua atenção ao social (Jamie Cason, 2007: 237).

A partir de uma perspectiva semiótica poderíamos dizer que a web 2.0 resulta na desmassificação do modelo de Shannon e Weaver depois da antropomorfização do mesmo realizada por Jakobson (1960). A atribuição de uma função específica a cada elemento, defendida pelo autor formalista, nos ajuda a entender o enorme impacto da web 2.0, 40 anos depois de sua formulação, ao integrar na própria estrutura a resposta (reação) do usuário (destinatário) da comunicação

Diante da constante transmissão inicial de informações pela Internet, quando o espaço virtual se considerava ainda pouco mais que um mero suporte 
do tráfico (a web 1.o não deixava de ser uma modalidade comunicativa dirigida a um receptor coletivo, ainda que não se tratasse simplesmente de uma massa), a web 2.0 se consolida progressivamente como um espaço social idôneo para estabelecer relações, comunidades ou outros sistemas de intercâmbio. Um cibermundo regido por normas similares às do mundo real, cuja tremenda influência baseia-se precisamente em sua incessante expansão pelo ciberespaço A importância das tecnologias eletrônicas e das redes sociais deve-se principalmente por estimularem a capacidade da pessoa a tomar decisões, criar valores, resolver problemas e colaborar com outros indivíduos (Tejedor, 2007: 9). Através da Rede, os jovens, seus usuários mais ativos, "conseguem uma apropriação simbólica de uma realidade com a qual se identificam e sentem-se parte do grupo de geração e, por que não, do mundo" (Rubio Gil, 2009: 84).

Não é por acaso que a revista Time tenha nomeado como o homem do ano de 2006 justamente o internauta, figurativizado em sua capa diante de um computador com um espelho ao invés de tela, onde aparecia a palavra "You". O semanário norte-americano homenageava, dessa maneira, "todas as pessoas que participaram da explosão da democracia digital", utilizando a Internet para difundir palavras e imagens, e contribuindo com o êxito planetário de algumas páginas como YouTube ou MySpace. A incidência da Internet em nossas vidas chega ao ponto de homologar nossa era como "a era da sociedade da Rede" (Rheingold, 2007: 119).

Esta espécie de revolução pacífica desencadeada pela Rede está incidindo notavelmente no modo como os meios tradicionais se comunicam. Cresce a tendência de que se passe de um modelo de tipo passivo (usuário que olha imagens ou escuta rádio a partir de uma linha de partida preestabelecida pela cadeia) a uma modalidade interativa (construção da programação via Internet ${ }^{8}$, contribuição da qual um dos maiores expoentes é o chamado citizen-journalism ou, como prefere denominá-lo Stefano Quintarelli, o jornalismo a partir de baixo (Quintarelli, 2007: 55). Por exemplo, a Current TV, o canal a cabo lançado pelo ex-vice-presidente Al Gore em 2005, ilustra a participação dos espectadores na produção, seleção e distribuição de conteúdos, com uma contribuição aproximada de $25 \%$ de tudo o que esta rede (network) ${ }^{9}$ emite. A digitalização e a abertura aos usuários do arquivo da BBC neste mesmo ano constituem outro hiato que Jenkins começa a chamar de Convergence Culture: um lugar onde os velhos e novos meios colidem (Jenkins, 2006), e um passo adiante na crescente integração dos usuários na Rede.

Mas sem minimizar em absoluto os múltiplos benefícios da Internet, Sonia Livingstone (2007) nos lembra também de alguns riscos que deveríamos levar em conta na hora de desenhar as políticas de alfabetização digital, como o incremento da desigualdade e da exclusão social ou os riscos inerentes à segurança e ao desenvolvimento social de crianças e jovens. A lista dos problema mais frequentes que a Internet enfoca em relação a estes dois últimos grupos de população inclui um conjunto de aspectos que não podem faltar em qualquer tipo de reflexão sobre a Rede, como a falsa segurança de anonimato que produz o envio de mensagens, a circulação de conteúdos hostis ou de assédio psicológico entre colegas ou conhecidos e, principalmente, a frequente confusão entre o público e o privado (Livingstone, 2007: 57). As conclusões de uma pesquisa recente dirigida por Ángeles Gil Rubio (Gil Rubio, 2009) também mencionam o risco de que os jovens aceitem "como normalidade ou realidade o que tão somente são efeitos de um meio ainda novo e não regulado", mas o estudo de Rubio demonstra assim mesmo que uma boa parte dos internautas jovens manifestam claras atitudes de recusa diante dos conteúdos incômodos da Rede.

De qualquer maneira, a questão sobre o controle da Internet representa hoje em dia uma faca de dois gumes, que na opinião dos experts ainda tardara a encontrar um ponto de conciliação entre aqueles que defendem postura opostas. As novas tecnologias da comunicação se situam em uma espécie de "zona franca imaterial" (Quintarelli, 2007: 56), cujas fronteiras são extremamente difíceis de determinar e, como assinala Henry Jenkins, ainda que algun clamem pela ausência de controle sobre os meios, outros sustentam que nunca estiveram tão controlados (Jenkins, 2006: 18)

Lawrence Lessig, jurista norte-americano de prestígio reconhecido, propõe aos governos do mundo que adotem um código misto, deixando em common (patrimônio comum) os recursos que uma privatização total estragaria irremissivelmente, para poder oferecer suas potencialidades intrínsecas de inovação e de criatividade a toda a sociedade. Se trataria, portanto, de regular de uma maneira ponderada a propriedade e o controle, aos quais se atribuiria uma cota minoritária em alguns setores específicos (como por exemplo o estrato físico), ainda que, ao contrario, o commons deveria levar a melhor parte do estrato do código (definido como o "coração" da Internet", com sua arquitetura fundamental eze e dos conteúdos (Lessig, 2006: 145).

De maneira mais específica, Lessig propõe uma validade quinzenal para o copyright renovável pelo autor ou, ao contrário, a obra passaria a domínio público. Tudo isso deveria ser feito mediante sistemas de e-government (a administração pública permitiria a autogestão da propriedade intelectual por meio da Internet, por parte de cada titular). Lessig também estimula uma análise séria das patentes, em relação aos custos e aos benefícios sociais que comportam, com o objetivo de reduzir de maneira mais ou menos drástica sua utilização, a qua no fundo considera uma espécie de monopólio legalizado (Lessig, 2006: 275). 


\section{JOVENS, TELEVISÃO E INTERNET}

A teoria da domesticação, que descreve o processo de adaptação por parte dos usuários a suas necessidades específicas, nos permite compreender em um sentido pragmático o passo da web 1.o para a web 2.o. Tal teoria, formulada inicialmente por Roger Silverstone (Silverstone e Haddon, 1996; Silverstone, 2006) para explicar a adoção e o uso das novas TIC no lar, reflete a recíproca e constante influência entre a tecnologia e a cultura, que foi capaz de configurar a Internet como um grande fórum público em escala mundial. A teoria da domesticação evidencia o papel ativo do usuário no pleno desenvolvimento do potencial tecnológico de cada nova aplicação e, em sua aliança com a televisão, converte o espectador ativo (o leitor-modelo de Eco redescoberto pelos Estudos Culturais nos anos 1980) em produtor.

Desde que a Comunicação incorporou o conceito de feedback de Norbert Wiener (cunhado no campo da mecânica para poder explicar os mecanismos de controle e funcionamento de um sistema), a retroalimentação converteu-se no horizonte (necessário, mas hipotético) de qualquer prática comunicativa. Diferentemente dos autores de Estudos Culturais, cujo background humanista levou-os a buscar os fundamentos da recepção (da audiência ativa) na Teoria da Cultura e na Teoria da Literatura, outros pesquisadores abriam novas vias no estudo da televisão reivindicando o papel da produção e da recepção na construção de significado (Newcomb e Hirsch, 1987).

Seguindo James Carey (1975), Newcomb e Hirsch entendem a comunicação como um processo de reconstrução e de renegociação da realidade e consideram os produtores como bricoleurs culturais. Uma qualidade que os citados autores também atribuem ao espectador, ao homologar sua projeção nos textos ou sua identificação com os personagens televisivos com a aspiração de muitos produtores de introduzir em seus programas ideias próprias ou de utilizar a televisão como um meio de expressão pessoal. Ainda que Newcomb e Hirsch não reivindiquem a bagagem semiótica-antropológica de sua proposta (filtrada através de Carey), sua concepção do bricoleur cultural é perfeitamente compativel com o uso do termo no uso da semiótica estruturalista aplicada para explicar a hibridização do sentido a partir dos anos oitenta. ${ }^{10}$

O conceito de bricoleur cultural de Newcomb e Hirsch parece-nos útil para definir, na atualidade, a crescente atividade de um espectador transformado em usuário, que se multiplica na Rede e introduz na interpretação retalhos de sua realidade cotidiana, inclusive de sua própria biografia. Um espectador transformado em uma constante fonte de inspiração para os responsáveis das diferentes produções, cujo feedbak através da Internet (chat, fóruns, blogs, redes sociais etc) configura uma viagem circular, de ida e volta desde a produção até a recepção, que engloba o paratexto (Genette, 1982) no texto, e a construção de significação na produção dos programas.

A ausência de uma programação específica para jovens, os videojogos e as redes sociais são algumas das causas de seu progressivo afastamento da televisão, ainda que a passagem do espectador passivo a protagonista na Rede também cumpra um papel importante na relação com a Internet dos nativos digitais. A assimetria e a unidirecionalidade da relação entre o emissor e o destinatário nos processos da comunicação de massas (McQuail, 1993), transforma-se com a web 2.0 em uma relação de natureza bidirecional e pessoal, em que o proprio usuário enriquece os conteúdos que recebe.

As novas tecnologias integram, portanto, diferentes níveis de comunicação: a comunicação textual, a comunicação icônica, a comunicação verbal, a comunicação diacrônica e sincrônica, a comunicação de massas e a comunicação interpessoal. Os conteúdos televisivos realizados pelos mesmos usuários constituem o novo desafio exposto pela Internet à televisão tradicional e, se não fosse pelos problemas que apresenta o copyright, muitos produtores já integrariam sem problemas as propostas dos internautas:

One option is that fans can give us everything, and we own it the minute that you do. We can make it into a TV episode or a film or anything we want, and we won't send you any money, and if we do it's just because we have a good sense of humour about it. Or we can say, 'I don't want to read what you do. It's not real because I didn't look at it.' Nobody has found a good solution much between that' (Paul Levitz, President and Publisher of DC Comics, 2009). ${ }^{1}$

A liberdade do usuário na hora de selecionar, introduzir, empacotar e etiquetar a informação (folksonomia), que lança à Rede uma vez selecionada introduzida, empacotada e etiquetada por outros usuários, ilustra o potencia de constante bricolage que implica a retroalimentação das comunicações através da Internet, com um grau de iniciativa pessoal e de autonomia difíci de imaginar há tão somente alguns anos. A web 2.0 é fundamentada para que os usuários, convertidos em produtores e organizadores de grades televisivas, passem a ser produtores, pesquisadores, agregadores de conteúdos e construtores de bibliotecas acessíveis mediante as modalidades de VoD ou Vídeo on Demand (Issepi, 2007: 265). Sem esquecer o constante desenvolvimento da tecnologia push, ou seja, daquelas ferramentas de comunicação nas quais o próprio sistema toma a iniciativa e é capaz de enviar conteúdos aos usuário de acordo com seus interesses como, por exemplo, a exploração de documento RSS (Rich Site Summary o Really Simples Syndication) associados aos blogs (Ribes, 2007).
11. http://www.dccomics. 15 nov de 2009. Floch, 1991. 
A relação, quase simbólica, que muitos espectadores ${ }^{12}$ estabelecem entre 12. Embora a malor parte dos telenautas sej jovem, os novos usuáric todo tipo de condiç̄ês características, cono assinalava ja desde o intio do seculo XXi expert em comunidades Baym (Baym, 2000: 203) televisão e as novas tecnologias constitui a maior aproximação à retroalimentação dos processos comunicativos na recepcão mediática realizada até o momento. Além disso, as pautas de uso da Internet, que descrevem novos padrões de ócio não são arbitrárias, mas reflexivas, e estão mudando os hábitos de uso do tempo livre, caracterizado pela valorização desse tempo livre "a la carte" (Gil Rubio, 2009). O estudo de tais padrões ou protocolos (estrutura do consumo) é necessário para poder determinar não apenas os âmbitos da inter-relação, mas também as diferentes modalidades dos discursos gerados a partir dos programas (sobre os personagens de ficção, sobre os atores, sobre si mesmo, sobre os discursos dos outros usuários etc).

As pesquisas sobre o consumo juvenil da Internet revelam que a dieta multimídia constitui a característica mais sobressalente da recepção entre esta faixa da população. O primeiro EIAA Media Multi-tasking Report, realizado pela European Interactive Advertising Association (EIAA), revela que o consumo simultâneo de diferentes meios aumentou em mais de $38 \%$ entre 2006 e $2009^{13}$. $\mathrm{O}$ informe proporciona dados interessantes sobre o perfil dos multi-taskers europeus, cuja maioria tem menos de 35 anos, $25 \%$ desses usuários têm entre 16 e 24 anos, enquanto que $29 \%$ oscilam entre 24 e 35 anos, a faixa etária que os publicitários denominam de Golden Youth. No entanto, também há indícios de que a televisão continue carregando um estigma social que leva frequentemente os entrevistados a calcular para baixo as horas dedicadas ao consumo televisivo fugindo do estereótipo do couch potatoe, enquanto contraditoriamente, superestimam o tempo dedicado aos outros meios. Por esse motivo, Jack Wakshlag, diretor de pesquisa da Turner Broadcasting, pede cautela na hora de interpretar os resultados das pesquisas sobre consumo mediático (Stelter, 2009).

Tradicionalmente, as pesquisas sobre os novos meios consideraram centrais as descrições dos efeitos que as diferentes modalidades comunicativas produzem e a maneira como os indivíduos se relacionam. No caso dos jovens, deve-se prestar atenção particular aos lugares de encontro virtual, transformados em espaços típicos das relações no ciberespaço, como os fóruns, chats, blogs ou as redes sociais. As redes sociais requerem uma atenção especial, pois constituem um dos principais instrumentos de comunicação entre os jovens, definidos como communitainment, pelas características que unem de comunidade, comunicação e entretenimento. A prática de coletivização do saber ou do intercâmbio de experiências é uma dinâmica fundamental na sociedade do conhecimento atual e os jovens de idades compreendidas entre 13 e 25 anos interagem de maneira natural com seus contemporâneos através de perfis nas redes sociais, que visitam cotidianamente ou até mesmo várias vezes por dia.
O sucesso das redes sociais se manifesta mediante a lista das 10 palavras mais populares no Google.es, denominada Zeitgeist 2009, que significa o espírito do tempo, com o qual se pode obter um panorama geral dos interesses e dos comportamentos dos espanhóis. Basta assinalar, portanto, que os primeiros quatro postos da lista são de espaços de socialização ${ }^{14}$ :

$$
\begin{array}{ll}
\text { 1. } & \text { tuenti } \\
\text { 2. } & \text { youtube } \\
\text { 3. } & \text { facebook } \\
\text { 4. } & \text { hotmail } \\
\text { 5. } & \text { marca } \\
\text { 6. } \text { as }^{15} \\
\text { 7. } & \text { yahoo } \\
\text { 8. } & \text { gmail } \\
\text { 9. } & \text { msn }
\end{array}
$$$$
\text { tradutor }
$$

O informe anual do ONTSI 2008 considera a importância atribuída ao uso das novas tecnologias para as redes sociais como a característica mais apropriada da mudança de atitudes dos usuários produzida neste ano. Uma mudança que coloca a Espanha em segundo lugar no uso de redes sociais a nível mundial, com $75 \%$ do total de internautas que as utilizam (10\% a mais que em 2007), de acordo com dados da consultoria Nielsen de 2009, recolhidos no informe citado.

\section{PORCENTAGEM DE VISITANTES NAS REDES SOCIAIS POR PAÍS}

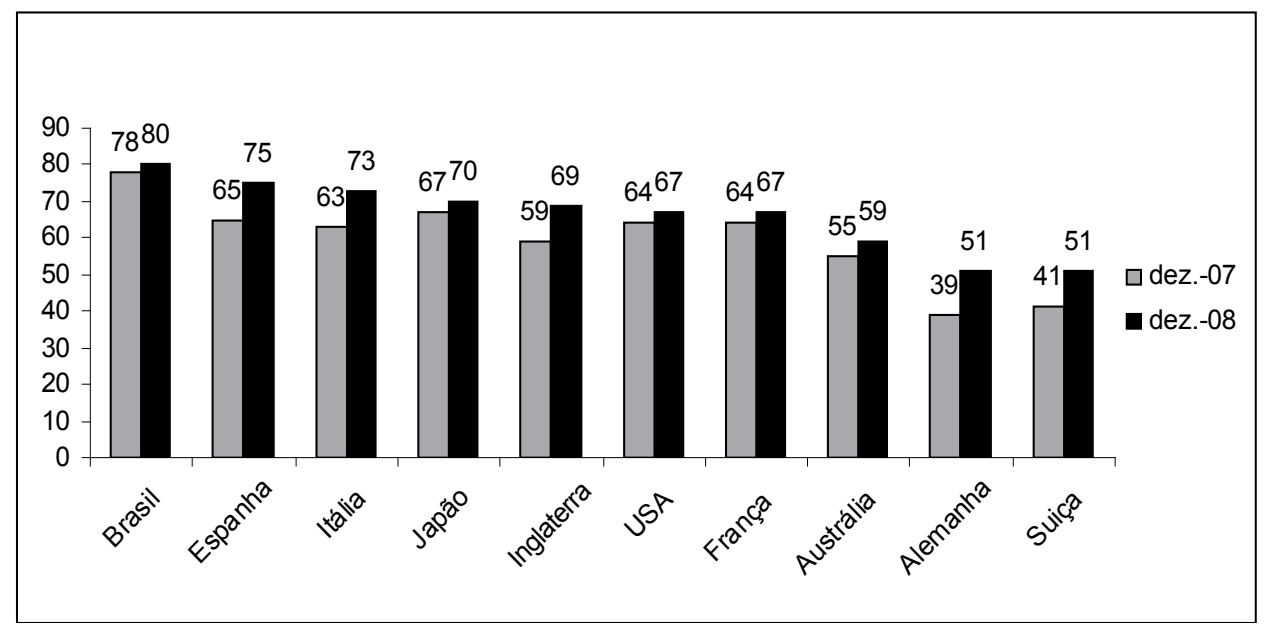

Fonte: Observatorio Nacional de las Telecomunicaciones y de la SI (ONTSI). A sociedade em rede 2008. Informe anual (2009: 62).
14. http://www. google.com/int//en/ press/zeitgeist2009/
regional.htmlıspain. Acesso em 3 dez. 2010. 
Marcelo Rinaldi classifica as redes sociais nos seguintes grupos: 1) redes sociais generalistas (MySpace, Facebook, Twitter etc); 2) redes de interesses (Flickr) e 3) redes de ação (reunião de assinaturas na web, Couch Surfing). Rinaldi assinala que será cada vez mais raro encontrar perfis bloqueados em uma única rede (network), pois tais perfis tenderão inevitavelmente a ser cada vez mais exportáveis, e utiliza o conceito de interoperabilidade para definir a crescente abertura de algumas redes sociais ao desenvolvimento de aplicações de terceiros que funcionariam desde o próprio sistema, como já ocorre com o Facebook (Rinaldi, 2007: 92).

O SpaceLift (uma ferramenta criada por Jess Martin e Drew Chen em 2007) constitui o primeiro exemplo paradigmático do uso cruzado do MySpace e do Facebook, que permite aos usuários de diferentes redes (network) conectaremse superando o sistema fechado de cada uma de ambas as redes sociais ${ }^{16}$. Em

(O) 61), o MySpace, a Microsoft e $o$ Google lançaram em 2008 o projeto "Identidade aberta", que permite aos usuários do MySpace utilizar o mesmo perfil pessoal e contrassenha em um grande número de sites (Flickr, YouTube, Blogger etc).

As comunidades de fãs de ficção televisiva, frequentadas por grupos restritos de seguidores de um determinado programa de ficção, constituem "versões digitais" dos fã-clubes tradicionais, onde cada participante se reconhece nos objetivos comuns do grupo e compartilha as mesmas paixões. As comunidades virtuais da Internet são associações de pessoas unidas por algum vínculo específico. As reuniões de "computer-savvy people", como os denomina Nancy Baym (Baym, 2000: 203), podem assentar-se sobre relações do tipo familiar, hobbies, interesses, paixões, trabalho etc, com o fim de compartilhar pensamentos, ideias, experiências etc (Prati, 2007: 35). No entanto, diferentemente dos velhos fã-clubes, trata-se sempre de lugares onde os contatos se estabelecem rapidamente, porque os usuários possuem um background comum que lhes permitem conectarem-se com os outros membros de maneira mais natural que em qualquer outra forma de CMC (Computer Mediated Communication).

A crescente interconexão entre a televisão e as novas tecnologias, junto com o atrativo que exercem entre os jovens, converteram os espaços de Internet em verdadeiras extensões dos programas, onde os internautas compartilham e retroalimentam suas interpretações mediante a contínua construção e desconstrução de comunidades interpretativas que se conformam e se deformam com a mesma velocidade com a que sucedem a maior parte dos programas. Tais comunidades preconizam uma nova era da televisão, caracterizada pela crescente apropriação dos textos televisivos por parte de uma recepção que substitui as tradicionais relações de identificação e de projeção por uma verdadeira produção de significação. Ainda que a função dos atuais fãs informáticos continue sendo a oficialização das "leituras comunitárias" da televisão (Pasquier, 2008: 86), a Internet expande os limites de interpretação do texto televisivo até extremos impensáveis - quando Umberto Eco formulou o conceito de obra aberta em 1962 - e materializa o "texto escrevível" definido por Roland Barthes em S/Z (1970) de uma maneira que nem mesmo John Fiske poderia sequer imaginar quando aplicou o conceito barthesiano à televisão em 1987.

Algumas redes sociais como Facebook, MySpace, Hi5, Tuenti etc estão desempenhando um papel decisivo na maneira de consumir televisão, mediante uma espécie de boca a boca da era digital que pode chegar a ser altamente efetiva, como assinala Sibyl Goldman, vice-presidente da área de espetáculo do Yahoo. Goldman parece convencido de que em pouco tempo "os tradicionai críticos da televisão passarão para segundo plano, substituídos pelas redes sociais, onde as pessoas seguem os conselhos de alguns usuários nos quais confiam como se fossem amigos" (GOLDMAN, 2009). Pode-se afirmar, portanto, que as redes sociais estão redefinindo o tradicional papel hipertextual da crítica até convertê-lo em uma relação paratextual com o programa ou o personagem sobre o qual escrevem:

That's how someone like Harry Knowles, a "morbidly obese" (his words) bearded Texan geek sitting in the dark in his mother's basement, ascended through his Ain't It Cool website to the status of his generation's Rex Reed, courted and fêted by major studios begging for his electronic approval (SALEM, 2009).

A Internet tirou os fãs das margens das indústrias da cultura de massas e os situou na mira de tais indústrias (Jenkins, 2006: 246). O geek começa a ser uma figura influente na sociedade atual e constitui peça-chave na construção de narrativas transmediáticas, assim como o eixo de um grande negócio que está modificando de maneira decisiva as relações entre a televisão e o resto das TIC, como assinala o crítico de televisão norte-americano Rob Salem:

Geek has become not only chic, but also massively influential. It spawns a billiondollar media business, transcending the traditional, rapidly eroding formats of broadcast television and theatrical release to encompass and overwhelm digital platforms, DVD sales and computer gaming (idem)

A Internet concede espaço a qualquer um que deseje expresar suas opiniões ou suas preferências, em um contexto onde o usuário é o protagonista, cria gera conteúdos e serviços de maneira ativa, satisfazendo sua necessidade de protagonismo, de sentir-se parte de uma comunidade. Atuar na web significa tanto escutar como falar, ler, escrever e ver. A televisão continua sendo o meio 
de comunicação hegemônico, mas a Rede, rica em conteúdos audiovisuais, cumpre uma importante função de acompanhamento e de aprofundamento dos conteúdos televisivos.

Seth Geiger (2009), presidente da empresa de consultoria mediática SmithGeiger afirma que "se continuará vendo a televisão no futuro, mas de maneira diferente" e fala de uma sinergia imediata entre televisão e Internet, desde o momento em que os conteúdos da televisão já constituem a premissa do sucesso da Rede:

82\% dos internautas veem vídeo na Internet e a porcentagem de episódios de série televisivas é a que cresce mais rapidamente. Em 2008, o consumo de vídeo na Rede aumentou em $51 \%$ enquanto que o da televisão passou de $59 \%$ a $54 \%$, apesar deste último meio continuar sendo o preferido pela comodidade que oferece o sofá à maior parte dos espectadores. ${ }^{17}$

17. Citado no artigo pe $2009 \mathrm{em}<\mathrm{chtp}: / / \mathrm{ww}$ cadenaser.com/tecnologia/ decidiran-programaciontelevisiva-futuro/scrcsrpo / 20090325 csrcsrtec_1/Tes $>$ Acesso em 14 set de 200

\section{FICÇÃO TELEVISIVA E INTERNET}

A ficção televisiva, o macrogênero predileto dos jovens, é recebida agora de uma maneira mais transversal, ou seja, através de qualquer meio que o abrigue. Os jovens se aproximam do que lhes interessa de maneira multimedial explorando todas as possibilidades a seu alcance. A grande oportunidade que a Internet representa para a indústria televisiva desloca os paradigmas tradicionais da comunicação de massas ao personalizar a informação e colocar a ênfase especificamente na atividade interpretativa da audiência.

De maneira especular, entre a esfera da produção e os espectadores também atua uma espécie de mecanismo de interação sinérgica, pois, ainda que uma parte das indústrias culturais trabalhem com vistas ao sucesso, cada vez fica mais difícil chegar a triunfar sem a devoção e a participação da audiência, materializada de maneira crescente mediante as formas de recepção e consumo na Internet. No entanto, por razões que nem os executivos das diferentes corporações, nem os especialistas em televisão conseguiram entender, a relação entre a televisão e a Internet não é recíproca e a ficção própria da Internet não continua a se desenvolver, a julgar pelo fracasso dos diferentes projetos dirigidos a produzir narrativas específicas para a Rede (cujo custo aproximado oscila entre 5.000 e 25.000 dólares para um Webisode de três a cinco minutos).

Contrariamente ao que se esperava após o lançamento em fevereiro de 2008 da Stage 9 Digital da Disney (que muitos consideravam o primeiro passo para a produçao massiva de ficção para Internet), nenhum dos 20 projetos anunciados pela companhia norte-americana viu ainda a luz, e a Stage fechou definitivamente em março de 2009. A dificuldade de competir com o YouTube é apontada como uma possível explicação (IMDB News, 2009), mas sem dúvida não pode ser a única. $\mathrm{O}$ fenômeno é, sem dúvida, muito mais complexo e talvez tenha mais a ver com uma possível troca de paradigmas narrativos do que com uma questão de hábitos ou preferências do espectador-usuário por uns meios ou por outros. Dessa maneira, poderíamos nos encontrar no princípio do fim da tradução intersemiótica (Jakobson, 1959; Eco, 2003), um feito sem precedentes na narrativa universal, caracterizada precisamente pela constante migração das histórias e dos motivos narrativos das transmedia storytelling.

Enquanto isso, na ausência de modelos narrativos específicos para a Internet (e para a telefonia móvel), a web está se convertendo em uma grande aliada da televisão, ao invés de competir com a pequena tela, como assinala o representante da Warner Brothers Media Group, Josh Schwartz, em uma entrevista concedida ao The New York Times:

But the company's larger strategy is to use the web to enhance TV viewing, not just replace it. To that end the creator of almost every network series is experimenting online, producing "brand extensions" to shows: blogs, back stories, even mini-episodes (Schwartz, 2009).

A presença crescente do vídeo na Internet, que segundo os experts poderia chegar a ocupar os 91\% do tráfico gerado na Rede em 2013, prospecta um futuro imediato no qual a participação dos usuários parece destinada a incrementarse de maneira exponencial, como assinala Marcos García Esteban, diretor da divisão de Áudio e Vídeo da Samsung na Espanha:

De agora em diante serão os usuários que criam seus próprios conteúdos, que deverão poder ser reproduzidos em qualquer suporte. De televisores a telefones celulares, e sem necessidade de nenhum intermediário. Agora, os discos rígidos multimídia são os que traduzem os arquivos de vídeo à televisão, no entanto, os novos televisores com acesso à Internet leem qualquer arquivo (García Esteban, 2009: 56).

Diante do espaço crescente que as redes sociais concedem aos vídeos (a recepção de imagens na Wikipedia já é iminente), as empresas televisivas se apressam a incrementar sua participação na Internet, convertendo uma presença inicialmente testimonial no verdadeiro motor de suas ficções de produção própria. Toda cadeia tem um site próprio, onde o usuário pode encontrar notícias, perfis e curiosidades sobre os personagens e os atores de seu programa favorito de ficção, assim como vídeos, fotos, episódios ou capítulos completos, enquetes, concursos, chat, blog, fórum e venda online de merchandising. 
Ao colocar em contato os emissores com os espectadores, a Rede favorece a desmediação, através dos comentários deixados nas páginas web (oficiais ou não oficiais) de uma série televisiva, ou das discussões abertas sobre episódios ou notícias dos atores. Por outro lado, a emissão de uma série pela Internet, depois de sua retirada da grade televisiva por causa de seu baixo rendimento em termos de audiência, é outro recurso que as cadeias começam a praticar com certa assiduidade, incentivado mediante a incorporação de vídeos sobre o making of do programa, fichas dos personagens, blogs, notícias, encontros digitais com os atores etc.

A frutífera retroalimentação entre a televisão e a Internet encontra seu correlato no crescente protagonismo da Rede nas representações da ficção, mais além de sua presença constante como telão de fundo das investigações policiais ou nas relações pessoais entre personagens. Dead inside, o sétimo episódio da quinta temporada de CSI: NY, inspira-se na Rede para construir o esqueleto
18. <http://postsecree. blogspot.com/> [Acess
em 22 jan. de 2009$]$

19. Episodio 76 (5ำ $4^{2}$ temporada), emitid
pela Teles em $27 \mathrm{~d}$ assassinato central desse episódio. Trata-se de Postsecret ${ }^{18}$, a web de Frank Warren onde os internautas publicam anonimamente seus segredos no formato de cartões ou post-it.

Em outro episódio de CSI:NY, Invisible Evidence ${ }^{19}$, Mark Taylor cria para si um perfil virtual no Second Life para tentar desvendar o assassinato de uma usuária dessa comunidade virtual. O final inconcluso desse episódio permitia aos espectadores converterem-se em colaboradores virtuais dos médicos forenses, mediante um bom exemplo de marketing experiencial que supunha o lançamento real da série no ambiente do Second Life. Os espectadores-usuários podiam intervir em um jogo que permitia escolher entre diversos níveis de participação: perambular por Manhattan com os detetives do CSI ou visitar um de seus laboratorios (primeiro nível); ter acesso à cena do crime e formular hipóteses sobre o assassinato (segundo nível); utilizar um kit virtual do CSI para interrogar os suspeitos (terceiro nível) etc. Damon Taylor, um dos criadores do laboratório virtual (produzido por Electric Ship) onde os internautas podem recriar as experiências realizadas no citado capítulo de CSI: NY, depois da colaboração entre a série e o Second Life apenas descrita, explica nos seguintes termos os diferentes níveis de transmedialidade derivados de tal colaboração:

We have a mystery game, and we will release a new one about every three weeks, which involves a crime scene, a crime lab, and suspects. It will be a 20-30 minute experience, and users can go to the crime scene, pick up evidence, process it, follow leads, and then choose the suspect they think committed the murder. The second mystery game is the Murder by Zuiker blog game. Every month, CSI Executive Producer Anthony E. Zuiker will draft a storyline. We will create that crime scene in a virtual context and invite people to visit that scene[...] The third mystery game is Finding Venus. Venus is a character from the show tonight, and we wanted to create an opportunity for a more sophisticated mystery game experience for those who want something a bit more challenging than the 20 -minute games. ${ }^{20}$

Do mesmo modo que ocorre no episódio Inside Evidence, a retroalimentação entre a televisão e a Internet permite aos emissores obter um feedback imediato e conhecer de maneira detalhada as exigências dos espectadores, para poder oferecer-lhes um serviço de mais qualidade. Como já antecipava Nicholas Negroponte em 1995, ao prever o colapso do broadcasting a favor do narrowcasting da era digital, a atenção foi se deslocando do grande público para públicos cada vez menores, até chegar a cada indivíduo (Negroponte, 1990).

\section{DO INTERNAUTA AO TELENAUTA}

Os jovens internautas iniciaram uma lenta, porém persistente migração da televisão à Internet, que lhes oferece a possibilidade de não depender da programação das cadeias ao personalizar seu próprio consumo, sua "grade ideal" (García de Castro, 2007: 10). O usuário, transformado de internauta em telenauta, agora juiz e parte dos programas que prefere, em virtude da multiplicidade de papéis que pode assumir através dos novos meios digitais. Daí que as cadeia televisivas tenham se curvado pouco a pouco ao poder da Internet e estejam tentando reverter em benefício próprio as numerosas potencialidades do luga privilegiado das conversações do terceiro milênio.

No verão de 2007 nascia o Vudu ${ }^{21}$, um serviço pago que permite o acesso nstantâneo a uma ampla oferta de cinema e televisão através da pequena tela sem computador nem conexão por cabo ou satélite. Mas em março do ano seguinte, $\mathrm{Hulu}^{22}$ já oferecia gratuitamente filmes e programas de televisão da NBC e da FOX, em troca de suas inserções publicitárias, além de incorpora serviços de outras webs como AOL, MSN, MySpace, Yahoo etc. Nesse mesmo ano, a WB.com contra-atacava a Hulu com séries on streaming populare como Buffy the Vampire Slayer (Buffy, a caça-vampiros) ou Veronica Mars, mas deixando claro que sua intenção não era substituir as emissões televisivas, mas enriquecê-las. "We're learning every single day [...] The metric for succes evolves as you go along", afirma Lisa Gregorian, vice-presidente executiva de marketing internacional do Brothers Television Group. ${ }^{23}$

Também o YouTube modificava em 2008 seu modelo de negócio e anunciava que emitiria a programação completa da CBS, inserindo publicidade antes e depois da emissão de cada uma das séries (atuais e clássicas) da cadeia norte-americana, para a qual estreava um reprodutor panorâmico e um modo de teatro (simulando as luzes apagadas de uma sala real). A Metro Goldwyn
20. Entrevista a Damon Taylor realizada por
Sam Ford <http://www henryjenkins.org/2007/10/ producing_the_csiny-
second life $1 . h$ html $>$. Acesso em 29 set 2009.
21. Vudue um sistema
de vídeo a la carte, con um pequeno dispositivo que se conecta a Interne am hard disk parecido TDT, que se conecta a rede através de uma porta Ethernet. <http:/// www.vudu.com/abou-
tus background.html> tus_background.html>
Acesso em 4 de fev 2010 . 22. Hulu utiliza o formato 22. Hulu utiliza o form resoluçāo que o YouTube, mas inferior à definição padrão da televisão, ainda que também conte com vídeos em 480p. <http:// www.hulu.com/> Acesso em 1 de jul 2009. 23. <http://www.nytimes.
com/2009/03/15/arts/ elevision/15karp.ht mllppagewanted $2 \& \mathrm{r}$
ef $f$ television $>$ Aces efftelevision> Acesso 27 de mar 2009 . 
Mayer (emissão de filmes) e a Apple (compra, download e reprodução de conteúdos através do iTunes) se juntaram pouco depois à iniciativa da network norte-americana. Sucessivamente, o YouTube lançava o programa de geração de ingressos YouTube Partnership Program (YPP), destinado inicialmente a incentivar a criatividade de seus usuários mais ativos mediante a colocação de anúncios nos vídeos que desejavam rentabilizar. ${ }^{24} \mathrm{Em}$ abril de 2009, o YouTube firmava um acordo com vários canais e produtoras (Sony, BBC, National Geographic ou Discovery) para distribuir alguns de seus filmes e programas pela internet mediante pagamento prévio dos mesmos. ${ }^{25}$

No momento de escrever estas linhas, todas as grandes redes norte-ame2009, Youfube abriu a ricanas (CBS, NBC, ABC, FOX, CW), assim como as cadeias a cabo (USA Network, TNT, Showtime, Lifetime, SyFy e ABC Family) oferecem episódios de suas séries online, disponíveis geralmente apenas nos Estados Unidos. Na maior parte dessas emissoras, a ficção também pode ser vista em HD e também em HQ ou em 108oP (full HD).

O eco da ficção na Rede também está modificando a atividade das redes sociais, com o Twitter à frente. No final de maio de 2009, o Twitter anunciava sua intenção de produzir uma série improvisada de televisão, junto com Reveille (responsável por títulos como The Office ou Ugly Betty) e Brillstein Entertainment Partners (Los Sopranos, Acording to Jim). Tal série contaria com uma plataforma cibernética que permitiria aos jogadores seguir a pista de algumas celebridades, um formato interativo e competitivo destinado a explorar outra nova via da promissora relação entre a ficção televisiva e a Internet.

Em setembro de 2009, a Fox apostava pelo Twitter anunciando que atores e produtores de duas de suas séries estrelas (a comédia musical Glee e a série de ficção científica Fringe) comentariam suas estreias e contariam relatos divertidos da gravação e curiosidades sobre ambas as séries, com a particularidade que a interação seria ao vivo e durante a estreia das séries (mediante as contas $@$ GLEEonFOX e @FRINGEonFOX).

Em novembro de 2009, o Twitter oferecia pela primeira vez uma versão f̧ção da popular rede social norte-americana. Mas a televisão basca (ETB-3) foi pioneira na Europa na hora de integrar o Twitter a um programa de televisão. Trata-se de Nick dut nit, um espaço dedicado exclusivamente à Internet, que permite a publicação direta das mensagens instantâneas dos telespectadores durante sua emissão, oferece a oportunidade de manifestarem-se sobre os conteúdos, manter uma conversa paralela na tela e até continuá-la depois que termina o programa. Além disso, contrariamente aos SMS que enviam habitualmente à televisão, $o$ Twitter, é gratuito. ${ }^{26}$
A mudança de hábitos no consumo midiático também afeta inevitavelmente a publicidade, que incrementa progressivamente seus investimentos na Rede em prejuízo aos meios tradicionais. A principal vantagem dos novos meios reside na possibilidade de direcionar a um target específico, apesar de continuar havendo dúvidas importantes sobre a adequação das mensagens aos novos suportes. Diante dos tradicionais estudos de mercado em busca de target, a Internet oferece de maneira crescente uma informação mais precisa sobre as características e as preferências desses novos nichos de espectadores, que configuram suas múltiplas e mutáveis identidades através das rede sociais ${ }^{27}$. Trata-se de um desafio para o profissional do marketing direto, que se vê obrigado a sair de sua toca e entrar em contato direto com o potencial consumidor, transformado em interlocutor e colega na Rede.

A Internet está se tornando a bíblia dos publicitários, que rastream potenciais consumidores nas comunidades online mais relevantes em função do produto que se queira promover, identificando os formadores de opinião e observando as interações dos usuários (social media monitoring). As nova tendências do setor publicitário traduzem-se em acordos com as cadeias, como por exemplo, os estabelecidos entre a Fox International Channels (que conta com títulos tão populares como Smallville, Ghost Whisperer, Prison Break, Hous ou Bones), e todas aquelas webs com conteúdos online capazes de entrar em contato diretamente com os seguidores das séries, para poder alcançar assim diretamente o público-alvo das inserções. ${ }^{28}$

Por outro lado, a Rede permite que publicitários realizem uma medição real dos contatos, desde o momento em que é possivel seguir os movimentos de cada usuário na página correspondente. Além disso, também se pode envia imediatamente uma mensagem específica, em função de uma determinada tipologia (mais ou menos detalhada) construída previamente. Trata-se, pois, de um procedimento sem precedentes no universo mediático, cujo horizonte é inegavelmente atrativo para os investidores.

Wetpaint, uma empresa de criação de páginas web, encontrou em 2009 uma maneira de medir a popularidade das séries norte-americanas rastreando toda semana seus títulos em algumas redes sociais como Facebook, Twitter e a sua própria, assim como no Google e em mais de meio milhão de sites de fãs, com o objetivo de elaborar um ranking semanal das 100 séries que mais deram o que falar. Diante de outros sistemas de medição já existentes no mercado ${ }^{29}$, a TVFandex, o instrumento utilizado por Wetpaint, apresenta-se como o primeiro sistema criado para oferecer uma comparação específica entre as séries rastreadas segundo a premissa de que o maior tráfico na Internet melhora a imagem da própria série e da rede de televisão e incrementa as vendas de seu merchandising.
27. El target, del cajón
al nicho $<$ htpp://www marketingdirecto. com/noticias/noticia. php?:idnoticia=30386>
Acesso em 20 out 2008 $<$ www.navegatv.com>, $<$ www.natgeoadventure. es $\rangle\langle$ www.pizquita.com $>$ 
Em janeiro de 2010, Nielsen anunciava o lançamento em setembro de Estended Screen, um novo programa de medição que incorporaria as audiências online de webs como Hulu, TV Everywhere (o projeto da Time Warner Cabo que se encontra em fase de testes) e Fancast Xfinity, a cadeia por assinatura Comcast Cable que começou em dezembro do ano passado. Não se mencionam, no momento, as páginas das Redes (Networks). ${ }^{31}$ Mas enquanto as iniciativas para poder chegar a conhecer os interesses do telenauta se multiplicam, cresce o desencontro entre emissores e investidores publicitários, considerando as declarações tranquilizadoras que os responsáveis das grandes redes realizam constantemente. ${ }^{32}$

O impacto enorme da ficção na Rede não corresponde, pois, com sua escassa rentabilidade em termos econômicos, mais além da formidável plataforma que representa para a promoção dos programas e a fidelização da audiência, e os publicitários querem mais garantias na hora de investir os aproximadamente 10 dólares que custa cada anúncio inserido em um vídeo. ${ }^{33}$ Até o momento, o problema de toda cadeia que optou pela estratégia de oferecer seus programas gratuitamente continua sendo o de saber como rentabilizá-los. E, para transformá-los em algo atraente para os investidores, estes últimos precisam saber como posicionar-se em relação à quantidade de usuários e aos minutos passados vendo o programa, como assinala o vice-presidente do setor de análise de meios da Nielsen, John Gibs. ${ }^{34}$

Nem mesmo o YouTube, o maior portal de Internet, se salva do incêndio, consciente de que para continuar sendo líder na Rede, está obrigado a oferecer conteúdos de melhor qualidade. Consequentemente, o YouTube continua ampliando seus acordos com grandes distribuidores de cinema e televisão, como por exemplo a Sony $y^{35}$, e se antecipa de novo à concorrência com iniciativas, como por exemplo, a estreia simultanea no portal e nos cinemas de Home, um filme documental de Luc Besson e Yann-Arthus Bertrand sobre a deterioração do planeta. ${ }^{36}$

Já não há praticamente nenhum programa de ficção televisiva que não experimente o online, produzindo todo tipo de brand extensions dos programas: blogs, histórias complementares ou até miniepisódios ${ }^{37}$. Qualquer coisa com o objetivo de atrair o espectador internauta para um desses paratextos infinitos a que dão lugar as modernas narrativas transmediáticas. Como assinala Chris Anderson, a Internet permite à televisão construir uma oferta de tipo long tail, onde cabe qualquer tipo de demanda ou de preferência ${ }^{38}$.

A parceria do Facebook com o fabricante de Cheetos para lançar a primeira série da popular rede social, Katalyst $H Q^{39}$, produzida pela sociedade de produção de Ashton Kutcher e distribuída pela aplicação FunSpace, responde à busca de diversificação das redes sociais, que também estão se posicionando em relação aos videogames, outros grande paraíso do lazer dos jovens. Por trás do sucesso nos sistemas online habituais dos jogos Flash e jogos para e-Phone, a multinacional francesa $U b i s o f t^{40}$ está desenvolvendo uma nova aplicação para Facebook que permite a inserção e a utilização de videojogos na web desta rede social. Paralelamente, a Microsoft anunciou a chegada iminente dos serviço de redes sociais, como o Facebook e o Twitter, o Xbox 36o, o portal de Games on demand ${ }^{41}$.

A colaboração entre CSI:NY e Second Life, mencionada anteriormente, permite entrever algumas posibilidades dos cruzamentos dos mundos virtuais com diferentes plataformas mediáticas. Mas, sobretudo, demonstra que as experiências virtuais, longe de constituirem um espaço para uma audiência de nicho, também atrai a audiência de massas, como assinala Damon Taylor por causa do sucesso obtido pela experiência pioneira deste tipo de narrativa transmediática, como citado a seguir:

This is not a niche industry or a niche technology. With creativity and hard work and expertise, it is possible to launch this type of crossover, and we are hoping that the CSI:NY Virtual Experience will begin to demonstrate that companie can use virtual worlds in ways that appeal to a larger audience. ${ }^{42}$

A Internet está minando as formas passivas dos meios tradicionais (imprensa, rádio, televisão etc), porque os jovens desejam interagir e contribuir para construir o conteúdo dos discursos mediáticos que chegam até eles ${ }^{43}$. No entanto, ainda que a Web esteja condicionando de maneira crescente o uso do demais meios ${ }^{44}$, não está substituindo-os. Diante da convicção do paradigma digital revolucionário de que os novos meios substituiriam os antigos, o paradigma moderno da convergência digital define a inter-relação entre uns e outro de uma maneira muito mais complexa (Jenkins, 2006: 6), em um momento histórico em que os velhos paradigmas se desintegram antes mesmo que os novos emerjam.

Jenkins remete-se a Ithiel de Sola Pool (1983) para explicar que a conver gência e a divergência são apenas as duas faces de um mesmo fenômeno, subscreve a hipótese deste autor sobre a inevitável incerteza que implica todo o período de transição por trás de cada nova mudança tecnológica (Jenkins, 2006: 11). Só que, diferentemente das etapas anteriores, o processo de remediação completado historicamente por todo novo meio (Bolter e Grusin, 2000), não termina de dotar a Internet de uma identidade específica. Assumamos, pois essa incerteza e continuemos explorando para não perder o passo da Rede e, de maneira mais específica, a passagem da televisão à Rede. M
40. <http://www.ubi. com/ES/default.aspx>
Acesso em 8 de fev 2010 . 41. <http://www. bladefm.es/2009/06/ relacion-con-la-web-20/ Acesso em 8 de fev 2010

42. Entrevista realizad m Damon Taylor por ham Ford em <http:///Www producing_the_csiny
second life_ll second_life_l.html que a Associação Mundial de Diários vai considerar confirmada em um estud
qualitativo realizado em 2007 com 100 pessoas de 10 países diferentes (EUA, Reino Unido, Sérvia, Suécia, Espanha, Líbano Filipinas e Japão) e embora reconheçam que a mostra não é suficientemente representativa, os autores da pesquisa consideram
determinante a precisão que deve revelar esta $e$ outras manifestações dos entrevistados. Cf. NOLLA, Santi, Avui, 10 30 http://paper.avui.cat/ article/dialeg/85841/ joves/premsa.html.

44. Stelter, B. "Hours a Day Spent on Screens,
tudy Finds", http://www nytimes.com/2009/03/27 business/media/27adco.
html?ref=televisions Acesso em 26 de mar 2009. 


\section{BIBLIOGRAFIA}

AUGÉ, Marc., Non luoghi. Milão: Eleuthera, 1993.

BAYM, Nancy K. Tune In, Log On: Soaps, Fandom, and Online Community. Thousand Oaks, CA: Sage Publications, Inc., 2000.

BERNERS-LEE, Tim, Tejiendo la red. El inventor de la World Wide Web nos descubre su origen. Madri: Siglo XXI, 2000.

BOLTER, Jay David. e GRUSIN, Richard. Remediation: Understanding New Media, First MIT Press paperback edition: 2000.

CAREY, James. "A cultural approach to communications". Communications, n.2, diciembre, 1975 .

CASON Jamie. "User generated content" (2007), en DI BARI, Vito. Internet è cambiato. E voi?, Milão: Edizioni Il Sole 24 Ore:, 2007.

ECO, Umberto. Dire quasi la stessa cosa. Milão: Bompiani, 2003.

The Role of the Reader. Indiana U.P, Bloomington, 1979.

European Interactive Advertising Association EIAA Media Multi-tasking Report, 2009. http://www.eiaa.net/Ftp/casestudiesppt/EIAAMediaMulti-taskingReport-PanEuropeanExecutiveSummary.pdf $>$ Acesso em 11 jun.2009.

FLOCH, Jean-Marie. Sémiotique, Marketing et Communication. Sous les signes, les estratégies. Paris : PUF, 1991

GENETTE, Gérard. Palimpsestes. La littérature au second degré. Paris : Seuil, 1982.

GARCIA ESTEBAN, M., "La vida es vídeo", in Quo, n. 167, agosto 2009.

GOLDMAN, Sybil. In: Las redes sociales decidirán la programación televisiva en el futuro. Cadena SER, 2009. http://www.cadenaser.com/tecnologia/articulo/redessociales-decidiran-programacion-televisiva-futuro/csrcsrpor/20090325csrcsrtec_1/ Tes . Acesso em 17 de set 2009

FISKE, John.Television culture. New York: Methuen \& Co. Ltd, 1987

IMDB News, 15 de junho de 2009. http://www.imdb.com/news/nio834349/ Acesso em 18 de mar de 2009.

JAKOBSON, Roman. "On linguistic aspects of traslation», en R. A. Browner (ed.), On translation, Cambridge (MA), Harvard University Press, 1959, págs. 232-239. _. "Linguistics and Poetics", in T. Sebeok, ed., Style in Language, Cambridge, MA: M.I.T. Press, 1960.

JENKINS, Henry. Convergence cuture: where old and new media collide. New York: New York University Press, 2006

LEMISH, Dafna. "Soap opera viewing in college: A naturalistic inquiry", in Journal of Broadcasting and Electronic Media , 29, 1985, pp. 275-293.

LESSIG, Lawrence. El codigo 2.o. Madri: Traficantes de sueños, 2006

LETIZIA, Marco. Usa: laudience tv sbarca sul web, «Lost» è il programma più visto, 4 março 2009, em <http://www.corriere.it/spettacoli/o9_marzo_04/tv_programmi _visti_internet_dati_nielsen_b27fffea-o8e1-11de-af33-0o144fo2aabc.shtml> Acesso em 18 set 2009.

LEVY, Pierre. Inteligencia colectiva por una antropologia del ciberspacio, Organizzazione Panamericana della Salute, Unità di Promozione e Sviluppo della Ricerca e il Centro Latinoamericano e dei Caraibi di Informazione in Scienze della Salute: 2004.

Qu'est-ce que le virtuel ?. Paris : La Découverte, 1995.

LIVINGSTONE, Sonia. Evalucion de los riesgos de Internet, en Cuaderno central: I televisión y la infancia, Telos 23, Fundación Telefonica, octubre-novembre 2007 pags. 52-69

MARKETING DIRECTO, El target, del cajón al nicho < http://www.marketingdirecto. com/noticias/noticia.php?idnoticia=30386> Acesso em 17 set 2009 .

MCQUAIL, Denis. Le comunicazioni di massa. Bologna: Il Mulino, 1993.

NEGROPONTE, Nicholas. Essere digitali. Milano: Sperling \& Kupfer, 1995.

NEWCOMB, Horace M., e HIRSCH, Paul M., Television as a Cultural Forum. Implication for Research, en Quarterly Review of Film Studies 8, 1983. Reprint in: Horace M. Newcomb (ed.): Televi-sion, The Critical View. New York: Oxford University Press 1987, pags. $455-470$

NOLLA, Santi. Joves I premsa, AVUI, 10 de junho de 2007, pág. 30.

ONTSI. Observatorio Nacional de las Telecomunicaciones y de la SI. A sociedade en rede 2008. Informe anual, 2009. < http://www.ontsi.red.es/informes-anuales/ articles/id/3779/informe-anual-2008-edicion-2009.html> Acesso em 9 de set 2009.

O'REILly, Tim. What is Web 2.o. Design Patterns and Business Models for the nex Generation of Software, 30 septiembre $2005 \mathrm{en}<\mathrm{http}: / /$ www.oreillynet.com/pub/a/ oreilly/tim/news/2005/09/30/what-is-web-20.html/> Acesso em 26 de mar de 2009. PRATI, Giuliano. Web 2.o. Internet è cambiato, Trento, Uni Service: 2007.

QUINTARELLI, Stefano. "Blog: se il medium è il messaggio, allora le persone sono il contenuto" (2007), en DI BARI, V., Internet è cambiato. E voi?, Milano, Edizioni Il Sole 24 Ore, 2007, pags. 56-57.

RED.ES Observatorio - ONTSI, Principales magnitudes de los contenidos digitales en Espana, < http://observatorio.red.es/contenidos-digitales/articles/id/3017/principales-magnitudes-los-contenidos-digitales-espana-2008.html $>$ Acesso em 19 de mar de 2009.

RED.ES Observatorio, Perfil socio demografico de los internautas, Analisi de dato INE 2008, Enero 2009, en < http://observatorio.red.es/hogares-ciudadanos/articles/ $\mathrm{id} / 3027 /$ perfil-sociodemografico-los-internautas-analisis-datos-ine-2008.html> Acesso em 20 de mar 2009 .

RHEINGOLD, Howard. Smart Mobs: The Next Social Revolution, Cambridge, Perseus Books Group: 2002 
RIBES, Xavier. "La web 2.o. El valor de los metadatos y de la inteligencia colectiva" (2007), en Cuaderno central: lat elevision y la infancia, Telos 23, Fundacion Telefonica, octubre-novembre 2007, pags. 36-43.

RINALDI, M., "Socializzare in rete: dai social network al digital self” (2007), en DI BARI, V., Internet è cambiato. E voi?, Milano, Edizioni Il Sole 24 Ore, 2007.

RUBIO GIL, Ángeles. Adolescentes y jovenes en la red: factores de oportunidad. Madrid: Instituto de la Juventud, 2009. http://www.injuve.migualdad.es/injuve/contenidos. item.action? $\mathrm{id}=1724774781 \&$ menuId $=572069434>$. Acesso em 9 de set de 2009

SALEM, R., Geeks gone wild, 27 marzo 2009 en <http://www.thestar.com/Entertainment/ Television/article/605201> Acesso em 18 set 2009.

SHANNON, Claude E. e WEAVER, Weaver., The Mathematical Theory of Communication, Illinois, The University of Illinois Press:, 1948.

SCHWARTZ, Josh. Welcome to the Net, Mr. “OC”. In: NY Times, 2009. <http://www. nytimes.com/2009/03/15/arts/television/15karp.html?pagewanted=2\&ref=televisi on Acesso em 18 set. 2009.

SILVERSTONE, Roger. e HADDON, Leslie. Design and domestication of information and communication technologies: technical change and everyday life, in R. Mansell \& R. Silverstone (Eds.) Communication by design: the politics of information and communication technologies, Oxford, Oxford University Press, 1996, pags. 44-74.

STELTER, Brian., 8 Hours a Day Spent on Screens, Study Finds, 26 marzo 2009 en $<$ http://www.nytimes.com/2009/03/27/business/media/27adco.html > Acesso em 14 de set de 2009.

STUDIO BRIEFING, Report: Networks Abandoning Online Programming, 15 de junio de 2009, <http://www.imdb.com/news/nio834349/> Acesso em 16 de set 2009.

SUROWIECK, J., Cien mejor que uno, la sabiduria de la multitud o por que la mayoria siempre es mas inteligente que la minoría. Barcellona: Urano, Tendencias, 2004.

TEJEDOR, Santiago. De la alfabetizacion digital a la alfabetizacion ciberperiodista, en Cuaderno central: latelevision y la infancia, telos 23, Fundacion Telefonica, octubrenovembre 2007, pags. 9

TISSERON, Serge. Hitchcock mia guéri. Paris: Albin Michel, 2003.

Artigo recebido em 23 de fevereiro e aprovado em 16 de março de 2010. 